\title{
Polypropylene/Polyamide/Carbon Fibres Nanocomposites: Processing - Morphology - Property Relationships
}

\author{
Laurentia Alexandrescu ${ }^{1}$, Maria Sonmez ${ }^{2}$, Mihai Georgescu ${ }^{3}$, Anton Ficai ${ }^{4}$, Roxana Trusca $^{5}$, \\ Ligian Tudoroiu 6 \\ ${ }^{1}$ National Research and Development Institute for Textile and Leather - Division Leather and Footwear Research Institute \\ Romania, INCDTP-ICPI \\ 93 Ion Minulescu St., sector 3, 031215, Bucharest, România \\ laurentia.alexandrescu@icpi.ro; maria.sonmez@icpi.ro; mihai.georgescu@icpi.ro \\ ${ }^{2}$ Faculty of Applied Chemistry and Materials Science, University Politehnica of Bucharest Romania \\ 1 Polizu St., 011061, Bucharest, Romania \\ anton.ficai@upb.ro; truscaroxana@yahoo.com \\ ${ }^{3}$ SC RONERA SA ROMANIA \\ 3 Serelor St., Bascov, Arges, 117045, Romania \\ ligian.tudoroiu@ronera.ro
}

\section{Extended Abstract}

The paper presents the study of new nanostructured polymer composites from polyamide/compatibilizers /polypropylene/carbon fibres nanoparticles-PA/PP-g-MA/PP/NCF to manufacture, by injection, bearing seals, contact plates, and other components for the railway industry, with shock resistance higher than $5-8 \mathrm{~kJ} / \mathrm{m}^{2}$, wear resistance below $100 \mathrm{~mm}^{3}$, resistance to temperatures of $-40-240^{\circ} \mathrm{C}$, resistance to impact and to outdoor applications, with temperatures ranging from -40 to $+60^{\circ} \mathrm{C}$, in rain, snow or sunshine.

Nanocomposites have been considered as a stimulating route for creating a new type of high performance material that combines the advantages of polymers (simple or combined) and nanoparticles. The disadvantage is that the polymers are usually not compatible and the preparation of compounds with suitable (mainly processing and physico-mechanical) properties is not performant [1].

Polyamide (PA) is a thermoplastic material, widely used in the industry, with varied applications (e.g. fibres, films, textiles, and various casting products) due to its mechanical and thermal properties [2]. Polyamide/polypropylene (PA/PP) composites are interesting because both components are relatively cheap, with advantageous properties, and are processable by melt blending [3]. The compatibilisation of binary polymer compounds can be made by the addition of graft copolymer, segments of which have physical or chemical affinity with two immiscible homopolymers [4]. In this case, polypropylene grafted with maleic anhydride (PP-g-MA) was used. Since PAs have great affinity towards water, they were mixed with $10 \%$ $\mathrm{PP}$ in order to increase its tensile strength and elasticity modulus.

Nano carbon fibres were selected (NCF), having remarkable properties resulting from the preferential orientation of crystals, parallel to the fibre axis, and referring to rigidness and very high longitudinal resistance, associated with very low linear expansion coefficient in the same direction [5].

The optimum formulation was used to prepare a series of nanocomposites under different technological conditions on the Plasti-Corder Brabender Mixer 350, using the following work method: at the temperature of $230^{\circ} \mathrm{C}$, polyamide is added (previously dried at $100^{\circ} \mathrm{C}$ for $10 \mathrm{~h}$ ), after softening and plasticizing, PP and the compatibility agent - PP-g-MA are added, temperature is set at $240^{\circ} \mathrm{C}$ and NCF is added for 3 minutes. Mixing continues at $250-280$ rotations/minute for 4 minutes, until all ingredients are embedded. Temperature is set at $200^{\circ} \mathrm{C}$ and mixing continues for 2 minutes for homogenisation. The mixture is taken out of the mixer and pressed into specimens.

The nanocomposites based on PA/PP-g-MA/PP/carbon fibres were characterized by scanning electron microscopy (SEM), Fourier transform infrared spectrum (FT-IR), and physico-mechanical tests.

In order to estimate the resistance to brittleness of polymer nanocomposites, they were tested by Izod shock resistance method. This determination is the most important one due to the fact that one of the requirements of polymer nanocomposites 
is optimized shock resistance, for use in heavy impact conditions. PA value is $2.5 \mathrm{KJ} / \mathrm{m}^{2}$. All nanocomposites tested have increased values compared to the control sample (PA), ranging between 10.29 to $15.76 \mathrm{KJ} / \mathrm{m}^{2}$. NCF concentrations higher than $1 \%$ led to decreases in shock resistance values similarly to tensile strength values.

\section{Acknowledgements}

This research was financed through PN-III-P2-2.1-PTE-2016, project: "New nanostructured polymeric composites for centre pivot liners, centre plate and other components for the railway industry - RONERANANOSTRUCT" supported by UEFISCDI Romania.

\section{References}

[1] L. Alexandrescu, M. Sonmez, A. Ficai, R. Trusca, L.Tudoroiu, "Polymer nanocomposites polyamide/oxidized graphite nanoparticles," in Conference Proceedings The 17th International Multidisciplinary Scientific GeoConference SGEM 2017, Nano, Bio, Green and Space - Technologies for a Sustenable Future, Issue 61, Section: Micro and nano Technologies, vol. 17, pp. 279-286, 2017.

[2] K. U. Aravind, G. Rajendra, S. T. Prakash and J. Shivraj, "Mechanical Characterisation of Polyamide 66/Graphite Nanocomposites," in International J of Materials Science, vol. 12, no. 3, pp. 411-420, 2017.

[3] A. Fasolino, J. H. Los, M. I. Katsnelson, "Intrinsic ripples in graphene," in Nat. Mater., vol. 6, pp. 858-861, 2007.

[4] W. S. Chow, Z. A. Mohd Ishak, "Polyamide blend-based nanocomposites: A review," in eXPRESS Polymer Letters, vol. 9, no. 3, pp. 211-232, 2015.

[5] M. Bhattacharya, "Polymer Nanocomposites - A Comparison between Carbon Nanotubes, Graphene, and Clay as Nanofillers," in Materials, vol. 9, pp. 262-297, 2016. 